\title{
Focusing capillary jets close to the continuum limit
}

\author{
ALFONSO M. GAÑÁN-CALVO* ${ }^{*}$ ROMÁN GONZÁLEZ-PRIETO¹ , PASCUAL RIESCO-CHUECA', \\ MIGUEL A. HERRADA ${ }^{1}$ AND MARÍA FLORES-MOSQUERA² \\ ${ }^{1}$ Department of Aerospace Engineering and Fluid Mechanics, ESI, Universidad de Sevilla, 41092 Sevilla, Spain \\ ${ }^{2}$ Ingeniatrics Tecnologías S.L., c/Trovador 3, 5A, 41018 Sevilla, Spain \\ *e-mail: amgc@us.es
}

Published online: 2 September 2007; corrected online 17 September 2007; doi:10.1038/nphys710

The demand for techniques that can reliably deliver and control nanometre-scale volumes of liquid is a growing priority in biotechnology and medicine. Capillary jets are capable of supplying a steady stream of monodisperse liquid droplets. But because of the increasing forces and pressures needed to counteract surface tension for droplets of decreasing size, reaching the nanoscale with such an approach is difficult. One way of overcoming such limitations is to electrostatically focus a jet as it emerges from a capillary. Another, which we report here, is to focus such a jet by hydrodynamic means, a double flow-focusing arrangement that involves a manifold capillary that delivers a second immiscible fluid jet that envelopes and guides the jet from an inner capillary. Under the appropriate working conditions, this enables the generation of continuous steady capillary fluid jets down to submicrometre diameter-approaching the ultimate continuum limit, which is supported by a proposed theory.

Focusing a fluid stream can lead to capillary jetting at extremely small scales. Here, we propose a gentle and strictly fluid-mechanical method to overcome the restoring force of surface tension, a force that increases in inverse proportion to the jet diameter and therefore sets a strict limit on the focusing rate. We describe a double flow-focusing arrangement where extensional forcing is mediated by the straining (or focusing) of an extremely slender fluid jet in the core of an immiscible liquid jet, which is in turn focused by a third current, an external gas stream forced through a small round orifice (Fig. 1). Such a double focusing arrangement guarantees that jet straining is locally stable everywhere upstream of the exit orifice. Eventually, the innermost jet breaks up into droplets downstream from the exit orifice, owing to the growth of capillary perturbations, whereas the intermediate stream remains stable. Droplet size is highly controllable and reproducible.

Submicrometre and nanometre geometries, including droplets, bubbles, capsules and fibres, occur in applications ranging from selective cell targeting to therapy ${ }^{1}$, in what can be classed as branches of unconventional nanotechnology ${ }^{2}$. It is well known that discrete and extremely small fluid units down to the molecular scale are naturally produced at droplet break-up in extensional and unsteady flows ${ }^{3}$. This extremely elusive flow-focused structure, where molecular scale is reached just before break-up, usually yields a train of extremely small droplets or bubbles ${ }^{4}$. Motivated by the need for a continuous controllable and gentle production of these fluid units, a compelling question is whether it would be possible by hydrodynamic means alone to indefinitely keep the last pinch-off ligament flowing. In fact, a steadily flowing, controlled liquid capillary jet may provide a continuous stream of roughly monodisperse droplets ${ }^{4-6}$ (refs 4,7 provide an introduction to the field). To achieve this, (1) the ligament must be turned into a continuous steady jet by supplying the fluid withdrawn by the issuing spout (for example, using the extremely precise syringe pumps currently available), and (2) an appropriate extensional steady flow must be maintained near the issuing spout.

Thus, a suitable downstream straining force on the jet is required to overcome the restoring tendency caused by surface tension, an unbounded trend inversely proportional to the jet diameter. Numerous studies following that of Taylor ${ }^{8}$ have dealt with this problem. Recently, a mechanism by which an infinitely thin steady fluid jet in a viscous extensional flow can be generated has been described by Zhang ${ }^{9}$, who found a mathematical solution to the problem. Its existence and stability, however, is a matter of controversy. In line with this and building on earlier studies, Suryo and Basaran ${ }^{7}$ have shown computationally, after a bold geometrical simplification, that a flow-focused stream under lowReynolds-flow conditions can easily be reduced by about two orders of magnitude. Besides, flow focusing ${ }^{5,710-19}$ provided a generic solution to steady micro-jetting from low to moderately high Reynolds flows. Flow focusing is attractive because of its purely hydrodynamic nature and continuous high yield. In particular, moderately high Reynolds axisymmetric flow focusing of a liquid jet by a gas $^{5}$ gives rise to droplets sized in proportion to the focused jet diameter on break-up, about two orders of magnitude smaller than the initial liquid stream.

Here, we show that combining low and moderately high Reynolds flow focusing, using a double flow-focusing arrangement, provides a fourfold size reduction, and possibly more, on a fluid stream. Thus, hydrodynamic means alone can provide a powerful and blur-free natural lens, where the minimal scale of the focused fluid, theoretically near the molecular scale, could be ideally mastered even below the resolution achieved by soft X-ray photolithography (the current Intel commercial processors' architecture score is $65 \mathrm{~nm}$ spatial resolution). This opens novel avenues for research in biomedicine ${ }^{20}$, biotechnology and material science. 

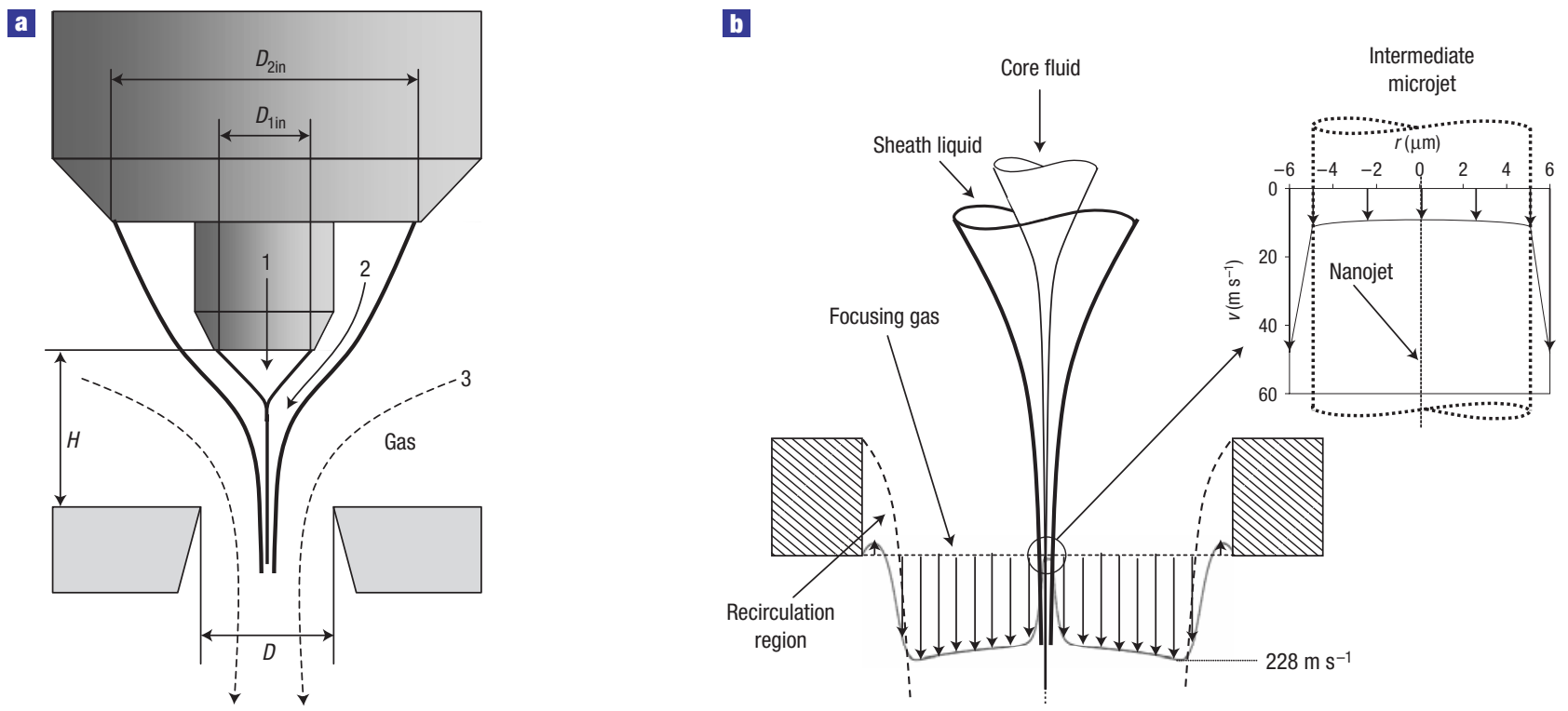

Figure 1 The double fluidic focusing arrangement. a, Co-flow-focusing geometry used: $D_{2 \mathrm{in}}=0.7 \mathrm{~mm}, D_{\text {1in }}=150 \mu \mathrm{m}, D=200 \mu \mathrm{m}$. $H$ ranges between 350 and $400 \mu \mathrm{m}$. The focusing fluid is air; the sheath and core fluids are immiscible (Table 1). b. Typical velocity profiles of the fluids at the exit orifice, as obtained by full numerical simulation (Fluent) using up to $10^{6}$ tesserae at the orifice region. Here, the air pressure drop applied through the orifice is $\Delta P=33 \mathrm{kPa}$, and the liquid $2 \mathrm{flow}$ rate is $0.44 \mu \mathrm{l} \mathrm{s}{ }^{-1}$ (further calculation details are given in a separate study, to appear elsewhere). No jet of core liquid 1 is simulated here owing to its extremely small size, inaccessible to any reasonable discretization.

\begin{tabular}{llll}
\hline \multicolumn{4}{l}{ Table 1 Physical properties of the fluids used in experiments $\left(T=25^{\circ} \mathbf{C}\right)}$. \\
\hline Fluids & $\mu$ (Pas) & $\rho\left(\mathrm{kg} \mathrm{m}^{-3}\right)$ & $\sigma$ (interfacial, $\left.\mathrm{N} \mathrm{m}^{-1}\right)$ \\
\hline Silicone oil I (SOI) & 0.1 & 968 & \\
Glycerol/water/ink (43:7:50 v/v) & 0.0045 & 1,122 & 0.01 (with SOI) \\
Silicone oil II (SOII) & 0.37 & 972 & \\
Pilot Ink & 0.037 & 1,070 & 0.011 (with SOII) \\
Mercury & 0.00153 & 13,600 & 0.4 (with SOII) \\
Air & 0.000018 & 1.2 & 0.03 (with SOII) \\
\hline
\end{tabular}

We departed from the path followed by others ${ }^{7,18,21,22}$, using a particular instance of extensional flow (see Fig. 1). Three fluids are involved: a core fluid 1, a sheath liquid 2 and an external gas 3 . A capillary jet of a viscous sheath liquid 2 is fed from a tube; the sheath flow is focused by a co-flowing gas stream issuing through a round orifice $^{5}$. The sheath flow 2 provides the background flow pattern for a core fluid 1, which is supplied by an axially located inner concentric tube. This tube sticks out about one diameter length from the outer tube feeding liquid 2 (Fig. 1a). Our hydrodynamic focusing system therefore consists of two lenses: an aerodynamic lens (gas 3) focuses the viscous liquid stream 2, which in turn acts as a second lens on the ultimately focused stream of fluid 1 .

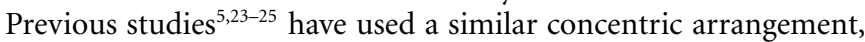
but with a completely different aim. Whereas they seek to break the intermediate current to produce double emulsions or structured particles, our aim is to preserve the stability of the intermediate current, to provide a uniform velocity background for the slender, extremely thin innermost filament.

The hydrodynamic double-lens system provides some remarkable advantages. First, the sheath jet 2, a viscous liquid, is gently shaped by the aerodynamic lens, an inexpensive co-flowing gas stream forced through the exit orifice and exerting negligible viscous resistance. Solid contact is thus avoided (Fig. 1b). Second, the focused stream of viscous sheath liquid 2 plays a stabilizing role (a function of the axial focusing rate) on the inner conical meniscus from which the innermost jet 3 issues. This stabilizing effect may originate from the positive shear stress caused on the surface of liquid 2 by the much faster gas stream 3, a consequence of the low gas-to-liquid density ratio. For illustrative purposes (Fig. 1b), an axisymmetric incompressible volume-of-fluid full numerical simulation code has been applied to an exemplary air-focused water micro-jet $(10 \mu \mathrm{m})$ through an orifice $(200 \mu \mathrm{m})$. Note the significant positive velocity gradient on the radial direction in the liquid near its surface (Fig. 1b, inset). This effect is absent when a liquid is used instead of a gas as the outermost focusing stream: in such a case, similar velocities are reached by all streams, significantly smaller than in the gas-focused case, and no appreciable positive radial gradients of velocities develop. This difference makes our system unique compared with other proposed configurations ${ }^{23,25}$. Third, to establish the required spatial focusing rate, the distance, $H$, between the smaller tube and the exit orifice and the sheath-liquid flow rate, $Q_{2}$, can be easily adjusted as a function of the viscosity ratio, $\mu=\mu_{2} / \mu_{1}$. Finally, the small cross-section of jet 2 at the orifice plays the role of a much smaller built-in orifice and provides a similar focusing effect: this eliminates the need for very large pressures and shear stresses on the viscous liquid 2, as would be the case if it were forced to flow through such a small in-built hole. The resulting core jet is tiny, well below the limit of conventional microscopy, provided the fluid 1 flow rate, $Q_{1}$, is sufficiently small (Fig. 1b). The method showed remarkable robustness, precision and reproducibility.

Experimental jetting is reported here for a variety of air-focused co-flowing jets whose physical properties are given in Table 1. Three liquid pairs focused by an external air stream, and an air-liquid-air combination have been investigated (Fig. 2): continuous jetting in the submicrometre range has been observed with (1) gas, (2) liquid solution (water solution) and (3) liquid metal, all co-flowed by air-focused oils ( $\mu_{2}=0.1$ to $0.37 \mathrm{~Pa}$ s). Fluid 1 density and viscosity ranged from $\rho_{1}=1.2$ to $13,600 \mathrm{~kg} \mathrm{~m}^{-3}$ (four orders of magnitude) 

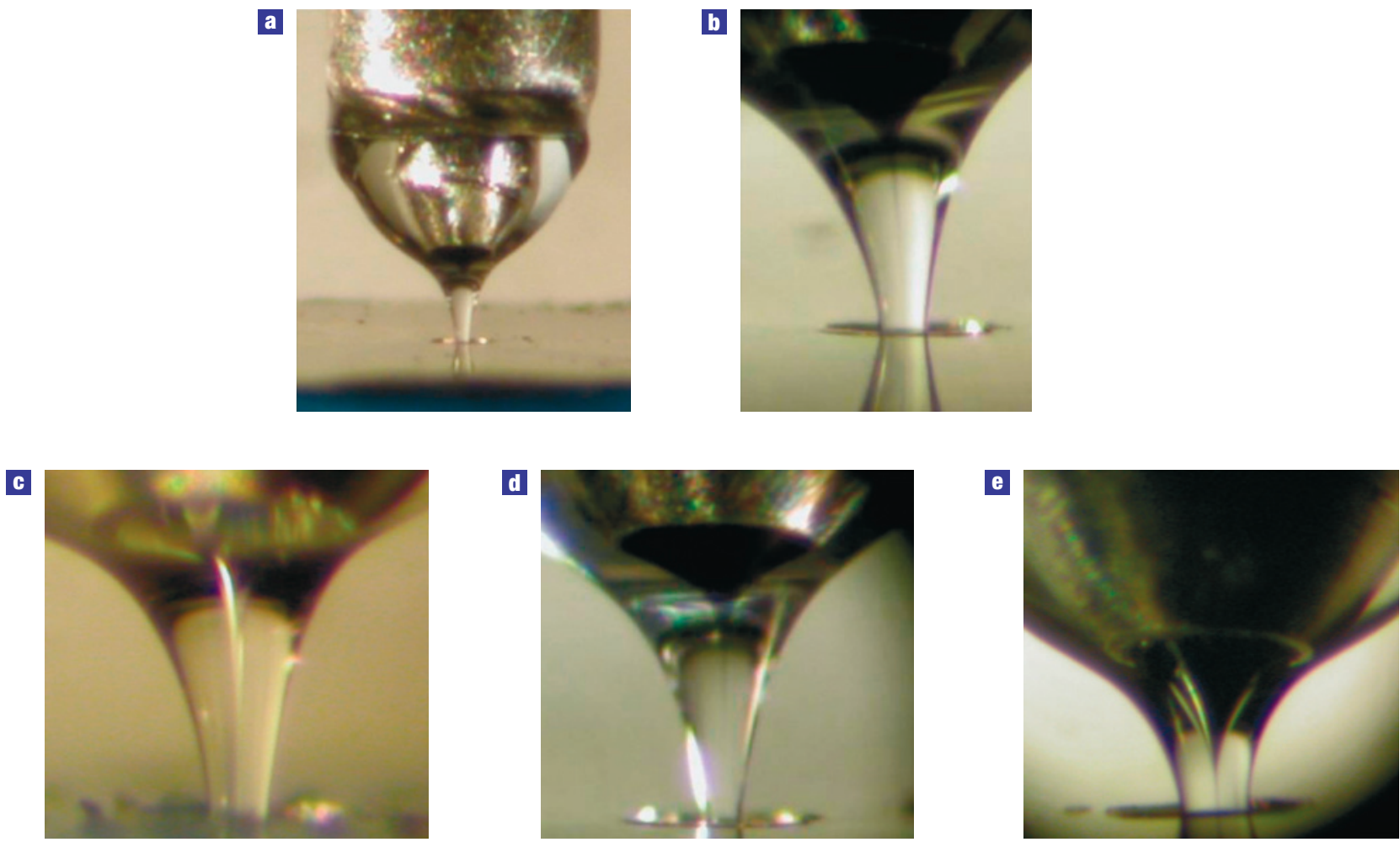

Figure 2 Pictures of the different fluid combinations used. a,b, Photographs showing the experimental set-up, and the negligible effect of a $75 \mu \mathrm{m}$ misalignment (b is a magnified picture of a). The jet remains centred in the orifice and the inner spout is unperturbed, showing robustness and reproducibility (arbitrary conditions). c, Air spout in oil, where $Q_{1}=30 \mu \mathrm{l} \mathrm{h}^{-1}$ (innermost flow rate), $Q_{2}=30 \mathrm{ml} \mathrm{h}^{-1}$ (sheath-liquid flow rate) and the oil jet velocity is $U=5 \mathrm{~m} \mathrm{~s}^{-1}$ at the exit orifice (as calculated by measuring the external jet diameter from the photograph and the flow rate, using the scale of the visible orifice diameter $D=200 \mu \mathrm{m}$ and assuming the liquid velocity profile to be flat). The gas pressure drop through the orifice was $\Delta P=85 \mathrm{kPa}$ and the viscosity ratio was $\mu=\mu_{2} / \mu_{1}=2.06 \times 10^{4}$. d, Ink solution spout in oil. Here, $Q_{1}=100 \mu \mathrm{h}^{-1}$, $Q_{2}=70 \mathrm{ml} \mathrm{h}^{-1}$, the co-flow velocity is $U=11.3 \mathrm{~m} \mathrm{~s}^{-1}$ (gas pressure $\Delta P=64 \mathrm{kPa}$ ) and $\mu=22.2$. e. Mercury spout in oil, where $Q_{1}=10 \mu \mathrm{h}^{-1}, Q_{2}=50 \mathrm{ml} \mathrm{h}^{-1}$, $U=4 \mathrm{~m} \mathrm{~s}^{-1}(\triangle P=85 \mathrm{kPa})$ and $\mu=2.42 \times 10^{2}$. The co-flowing oil is focused by an external air stream in all cases.

and from $\mu_{1}=0.000018$ to $0.037 \mathrm{Pas}$ (Table 1 ). The interfacial tension of the co-flowing pair ranged from $\sigma=0.01$ to about $0.4 \mathrm{~N} \mathrm{~m}^{-1}$. The orifice diameter was $D=200 \mu \mathrm{m}$ and the ambient temperature was $T=25^{\circ} \mathrm{C}$.

Figure 2a,b shows the double-focusing set-up and the negligible effect caused by misalignment. Figure $2 \mathrm{c}$ shows an air spout for the air-in-silicone-oil-II combination (Air-SOII); Fig. 2d shows the case where silicone oil I is the co-flowing liquid 2 and a glycerol/water/ink mixture is the inner liquid 1 (GWI-SOI); finally, Fig. 2e shows the mercury-in-SOII configuration (Hg-SOII).

It is worth mentioning that the fluid 1 flow rates, $Q_{1}$, in Fig. 2 are selected to make sure that the issuing jet remains visible; no other restriction is observed. Indeed, in all cases investigated under the appropriate focusing distance, $H, Q_{1}$ was reduced below $1 \mu \mathrm{h} \mathrm{h}^{-1}$ without any dripping signal (jittering or blurring) at the conical apex ${ }^{9}$ of the inner meniscus (Fig. 2). A continuous and steady inner liquid filament could be optically observed, but hardly so for the smaller inner liquid flow rates used: further reduction led to length scales well beyond our optical scope.

Furthermore, Fig. $3 \mathrm{a}-\mathrm{c}$ shows a case where an ink-in-oil dispersion was collected (P.Ink-SOII) and the droplets were optically measured using an optical transmission microscope (OLYMPUS BX61). Here, the co-flowing oil flow rate is $Q_{2}=10 \mathrm{ml} \mathrm{h}^{-1}$ and $U=11.6 \mathrm{~m} \mathrm{~s}^{-1}(\Delta P=60 \mathrm{kPa})$. The viscosity ratio is $\mu=10$. Each picture results from the combination of at least four direct instantaneous photographs with digital background subtraction. We set the focus at the minimum droplet image blurring, the main hindrance close to and below the light wavelength. Figure $3 \mathrm{~d}$ shows a plot of the measured droplet size compared with a simple theoretical prediction, assuming that viscous diffusion makes both fluids 1 and 2 move with the same velocity downstream of the exit orifice, which gives: $d_{\mathrm{g} 1} / d_{2}=1.89\left(Q_{1} / Q_{2}\right)^{1 / 2}$. Here, $d_{\mathrm{g} 1}$ indicates the droplet diameter resulting from the innermost jet decay. The factor 1.89 comes from the classical Rayleigh's prediction. Estimated droplet sizes down to about $220 \mathrm{~nm}$ are given, where measurement error is assumed to be commensurate with half of the illumination wavelength.

Figure 4 shows results from the mercury-in-SOII configuration (Hg-SOII). At the lowest flow rate $\left(Q_{1}\right)$ tested, the mercury spout became almost invisible with our optical microscope. Observation below that point became unreliable. It is worth noting that mercury purity and oil cleanness are required to obtain completely jitterfree steady jetting. Metal bulk and/or interface contamination give rise to slight but noticeable interface perturbations, which seem to vanish as the liquid spout size decreases (jet diameter in the micrometre size and below).

In the following, we provide a more detailed theoretical background to the experimental phenomena described above. A first fundamental requirement to achieve steady focused jetting is that the microscopic issuing jet must be locally stable, that is, the external straining force must guarantee that any natural perturbation on the issuing jet does not grow locally and is flushed 

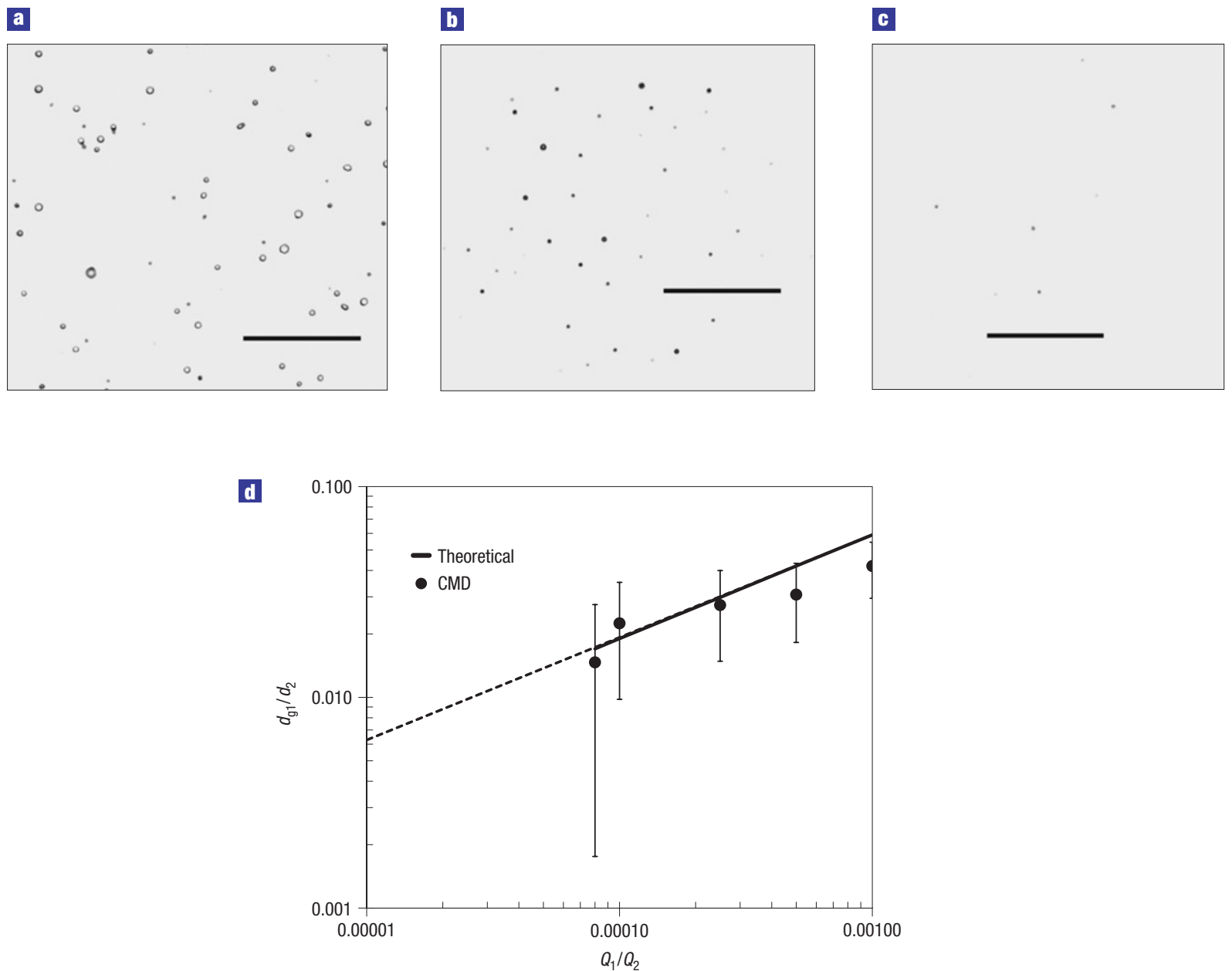

Figure 3 Pilot Ink droplets dispersed in Soll by co-flow focusing. Droplet dispersion obtained with $\triangle P=60 \mathrm{kPa}, Q_{2}=10 \mathrm{ml}^{-1}$. a-c, Droplets photographed using a $\times 1000$ optical microscope (Leica), after digital background subtraction (four photographs are combined in each picture); the inner liquid flow rate $Q_{1}$ is 10 (a), 2.5 (b) and 0.8 (c) $\mu \mathrm{l} \mathrm{h}^{-1}$. The scale bars are $10 \mu \mathrm{m}$. d, Drop size, $d_{91}$, scaled with the sheath-liquid jet diameter at the exit orifice, $d_{2}$, for five liquid flow rate combinations $Q_{1} / Q_{2}$. CMD in the label indicates the experimental droplet count mean diameter obtained from images. Obviously, optical errors make measurements highly imprecise below visible light wavelengths.

downstream (that is, the jet is at least convectively unstable). Jetting is replaced by unsteady dripping ${ }^{10,13,26-30}$ below a threshold flow rate in the absence of surfactants or electric fields ${ }^{31,32}$. Below the threshold flow rate, no issuing spout is observed, and relatively large droplets or bubbles are formed ${ }^{25}$ under the restoring role of surface tension, a phenomenon arising from the unbounded local growth of axisymmetric capillary waves.

To systematically analyse the existence and stability of the extremely thin focused jets observed, we used a wellestablished spatiotemporal instability analysis formalism to search for their jetting-dripping transition, a concept inspired by the dripping-tap ${ }^{33}$ phenomenon. It has recently been linked to the convective/absolute capillary instability transition of the issuing jet $^{19,26,28,30,34-36}$, with very promising prediction power. The linear convective/absolute instability analysis of a capillary fluid jet with density $\rho_{1}$ and viscosity $\mu_{1}$, co-flowing in an immiscible liquid of density $\rho_{2}$ and viscosity $\mu_{2}$, has been the subject of numerous recent articles ${ }^{19,28,29,35,36}$. Previous studies ${ }^{34}$ showed the intrinsic link between the convective/absolute transition in linear spatiotemporal instability analysis and jetting-dripping transition in experiments. When viscous effects are accounted for ${ }^{19,28,35-37}$, this link can be extended to extremely slender inner jet diameters, that is, when the Reynolds numbers $\operatorname{Re}_{1}=\rho_{1} U R / \mu_{1}$ or $\operatorname{Re}_{2}=\rho_{2} U R / \mu_{2}$ are sufficiently small, $R$ being the innermost jet radius and $U$ being the convective velocity of both fluids. Here, we have used a linear spatiotemporal model given elsewhere ${ }^{19,29,35,36}$ to predict the jetting-dripping transition of fluid jets produced in the submicrometre and nanometre range (necessarily implying $\mathrm{Re} \rightarrow 0$ ). Taking advantage of the large outer-to-inner jet diameter ratio, the intermediate liquid 2 can be conceived as an infinite background surrounding and sheltering the innermost jet with a local nearly uniform axial velocity field. The jets in the theory are infinite in extent, whereas the real jets in the experiments emanate from a nozzle and hence are of finite length; this difference, however, does not modify the bulk of the ensuing deductions. Thus, we interrogated the system searching for the smallest possible jet diameter. To our surprise, the system response was invariant as the jet diameter approached zero: according to the model, the dripping-jetting transition takes place for a given viscosity ratio, $\mu$, at a certain downstream speed of the outer co-flowing liquid, independently of the inner spout size. Above this speed, or alternatively, above a certain external viscosity threshold for a given co-flow speed, the theory shows that steady jetting is always possible, and continuous jetting can 

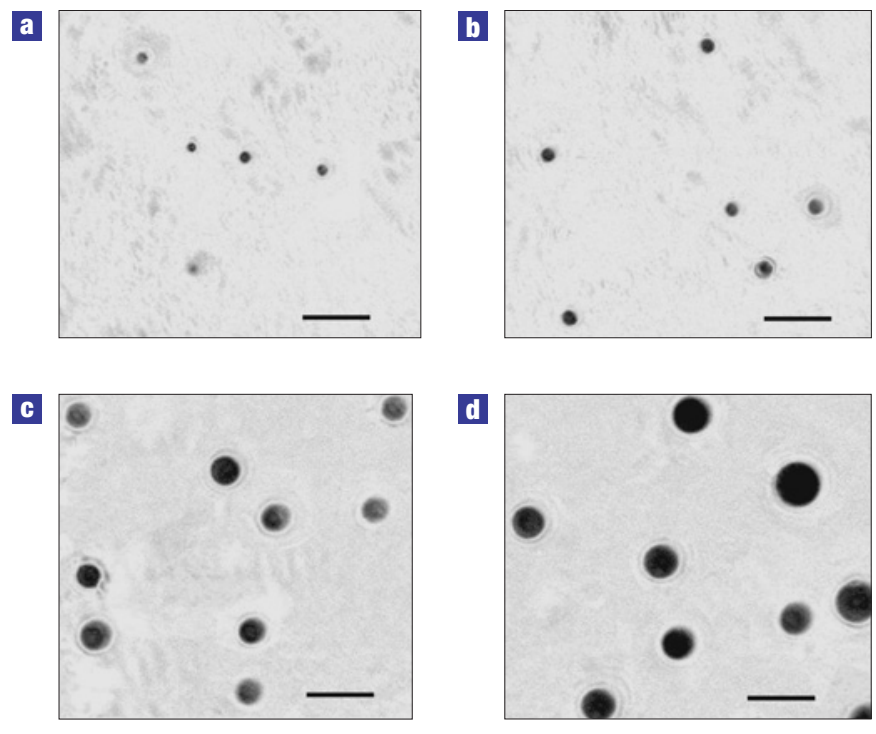

Figure 4 Photographs of mercury droplets obtained using a mercury-silicon oil II-air combination at different experimental conditions. a-d, Neglecting start/stop transients, droplets were collected approximately under the conditions $\Delta P=85 \mathrm{kPa}, Q_{2}=50 \mathrm{ml} \mathrm{h}^{-1}$ and $Q_{1}=5(\mathbf{a}), 10(\mathbf{b}), 50(\mathbf{c})$ and $150(\mathbf{d}) \mu \mathrm{lh} \mathrm{h}^{-1}$. The average droplet sizes in a-d are $600 \mathrm{~nm}, 950 \mathrm{~nm}$ (less than $10 \%$ standard deviation in this case), 2 and $3 \mu \mathrm{m}$, respectively. The micrographs were obtained as in Fig. $3 \mathrm{a}-\mathrm{c}$. The scale bars are $5 \mu \mathrm{m}$.

be preserved by viscous co-flow down to the smallest continuum scale. As an eventual break-up preserves the jet scale, it follows that fluid threads, droplets, capsules or fibres of arbitrarily small size can be gently, precisely and continuously produced by pure hydrodynamics and the appropriate choice of the geometry and flow configuration.

For convenience, here we define a combined capillary number $\mathrm{Ca}=\left(\mu_{1} \mu_{2}\right)^{1 / 2} U / \sigma$, where $\sigma$ is the fluid-1-to-liquid-2 interfacial tension. In the small-Re limit, the transitional $\mathrm{Ca}^{*}$ between jetting and dripping is found to be a universal function of the viscosity ratio, $\mu$, alone (see Fig. 5). This means that for liquid speeds $U>\sigma\left(\mu_{1} \mu_{2}\right)^{-1 / 2} \mathrm{Ca}^{*}$ (corresponding to an average capillary velocity between liquids 1 and 2), jetting would be observed in the low-Re limit down to previously unimaginable small sizes, in agreement with the experimental observations provided here. This fundamental theoretical result has been consistently confirmed in a range of twelve orders of magnitude in $\mu$, from $\mu=10^{-6}$ to $10^{6}$. Although from a very different system set-up, a similar trend of $\mathrm{Ca}$ values can be observed in the recent unsteady simulations of Suryo and Basaran ${ }^{7}$ in co-flowing liquids, with $\mu$ ranging from $10^{-2}$ to $10^{2}$. Unfortunately for our purpose, the apex of their pointed meniscus from which the liquid spout issues, flows with a highly unsteady velocity, making a comparison with our steady analysis hardly justifiable.

Our experimental observations are tested against theory in Fig. 5. First, for the fluid combination Air-SOII (Fig. 2c), the critical capillary number is $\mathrm{Ca}^{*}=0.14$ (here, $\mu=2.06 \times 10^{4}$ ), whereas the corresponding capillary number of the experiment is $\mathrm{Ca}=0.43\left(U=5 \mathrm{~m} \mathrm{~s}^{-1}\right)$, larger than $\mathrm{Ca}^{*}$. Consistently, gas jetting is observed in the experiment. Furthermore, in the GWI-SOI combination (Fig. 2d), Ca $=24.03\left(U=11.3 \mathrm{~m} \mathrm{~s}^{-1}\right)$, about two orders of magnitude above the critical $\mathrm{Ca}^{*}=0.175$ applicable in this case $(\mu=22.22)$, supporting the observation

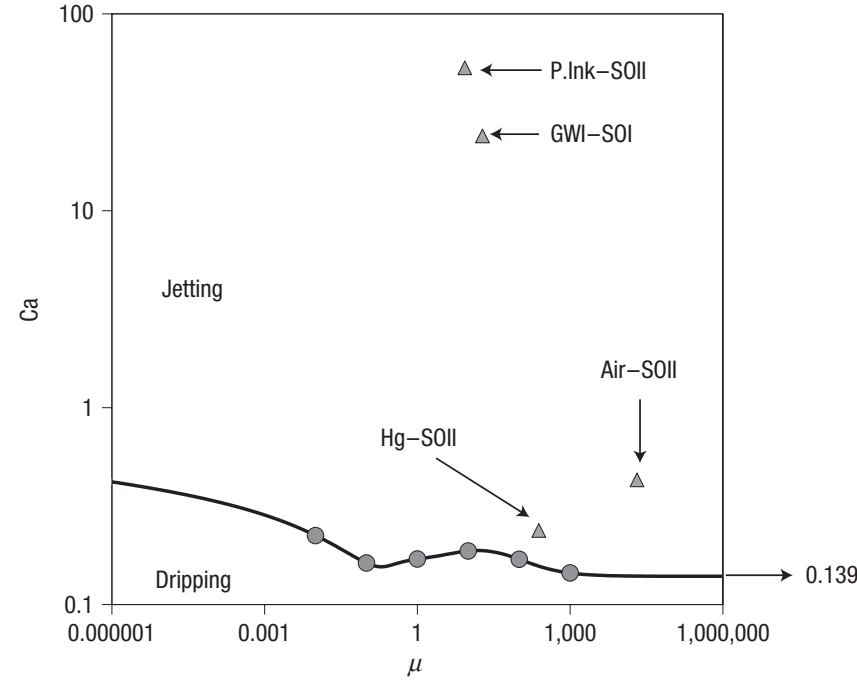

Figure 5 Plot of the jetting-dripping transition location in the capillary number-viscosity ratio plane. Transition values $\mathrm{Ca}^{*}=\mathrm{Ca}^{*}(\mu)$ are obtained using an analytical dispersion relation ${ }^{19,35}$, in full agreement with the numerical results (circles) from a full Navier-Stokes code described in ref. 35 (in the range numerically explored, between $\mu=10^{-2}$ to $\left.10^{3}\right)$. The early prediction formulated in Gañán-Calvo et $a l^{35}$, that is, $\mathrm{Ca}^{*}=0.139$ valid for large $\mu$ values, is apparent here. Triangles are located at the four parametrical cases of Figs 2-4: GWI-SOI, P.Ink-SOII, Hg-SOII and air-SOll, respectively.

of jetting. Besides, in the P.Ink-SOII combination (Fig. 3, $\mu=10.0) \mathrm{Ca}^{*}=0.187$, whereas the experimental $\mathrm{Ca}=53.2 \gg \mathrm{Ca}^{*}$ $\left(U=5 \mathrm{~m} \mathrm{~s}^{-1}\right)$. The largest $R$ at the exit orifice obtained with this combination is about $0.4 \mu \mathrm{m}, \mathrm{Re}_{1}=\rho_{1} U R \mu_{1}^{-1}=0.057$ and $\operatorname{Re}_{2}=\rho_{2} U R \mu_{2}^{-1}=0.0053$, which justifies our approximation. In the $\mathrm{Hg}$-SOII combination (Fig. 4), $\mathrm{Ca}=0.238$, whereas the critical value $\mathrm{Ca}^{*}=0.171<\mathrm{Ca}\left(\mu=2.42 \times 10^{2}\right)$. Thus, jetting is still theoretically possible, in accordance with the experimental observation. However, being that close to the threshold (Fig. 5, close to the solid line) sets stringent conditions: the feeding tube must be sufficiently close to the orifice (Fig. 2e) to ensure that the pressure gradient overcomes the axial force resulting from the surface tension at the cusp vicinity. Creeping flow conditions still apply in this case $\left(\rho_{2} / \rho_{1}=0.071, \mu=2.42 \times 10^{2}\right)$ for mercury jet diameters in the range of $1 \mu \mathrm{m}$ and below. In summary, the experiments presented seem in full agreement with theoretical predictions and pave the way for general application of this technique.

\section{METHODS}

The experiments shown in Figs 2 and 4 have been carried out under air suction. The oil phase used as the co-flowing agent is fed through a stainless-steel tube (Fig. 2c-e; outer diameter $=1 \mathrm{~mm}$, inner diameter $=0.7 \mathrm{~mm}$ ). The fluid phase in the spout is fed through a stainless-steel capillary tube (outer diameter $=0.38 \mathrm{~mm}$, inner diameter $=0.15 \mathrm{~mm}$ ) concentric with the former tube. This latter tube protrudes $0.45 \mathrm{~mm}$ from the external one. The liquid pair was sucked from the atmospheric condition through an orifice $(D=0.2 \mathrm{~mm})$ aligned with the concentric feeding tubes. The suction orifice is drilled in a stainless-steel plate $75 \mu \mathrm{m}$ thick, attached externally to the cap of a small reservoir. The distance from the inner feeding tube exit and the orifice is selected to assure that the applied pressure gradient at the orifice vicinity overcomes the axial force resulting from the surface tension. The oil was slowly collected in the reservoir at a reduced pressure. 


\section{Received 12 January 2007; accepted 2 August 2007; published 2 September 2007.}

\section{References}

1. Whitesides, G. M. Nanoscience, nanotechnology, and chemistry. Small 1, 176-179 (2005).

2. Gates, B. D., Xu, Q. B., Love, J. C., Wolfe, D. B. \& Whitesides, G. M. Unconventional nanofabrication Annu. Rev. Mater. Res. 34, 339-372 (2004).

3. Stone, H. A. Dynamics of drop deformation and breakup in viscous fluids. Annu. Rev. Fluid Mech. 26, 65-102 (1994).

4. Eggers, J. Nonlinear dynamics and breakup of free-surface flows. Rev. Mod. Phys. 69, 865-929 (1997)

5. Gañán-Calvo, A. M. Generation of steady liquid microthreads and micron-sized monodisperse sprays in gas streams. Phys. Rev. Lett. 80, 285-288 (1998).

6. Xu, S. et al. Generation of monodisperse particles by using microfluidics: Control over size, shape, and composition. Angew. Chem. Int. Edn 44, 724-728 (2005).

7. Suryo, R. \& Basaran, O. A. Tip streaming from a liquid drop forming from a tube in a co-flowing outer fluid. Phys. Fluids 18, 082102 (2006).

8. Taylor, G. I. The formation of emulsions in definable fields of flow. Proc. R. Soc. Lond. A 146, 501 (1934).

9. Zhang, W. W. Viscous entrainment from a nozzle: Singular liquid spouts. Phys. Rev. Lett. 93, 184502 (2004).

10. Gañán-Calvo, A. M. \& Gordillo, J. M. Perfectly monodisperse microbubbling by capillary flow focusing. Phys. Rev. Lett. 87, 274501 (2001).

11. Anna, S. L., Bontoux, N. \& Stone, H. A. Formation of dispersions using flow focusing in microchannels. Appl. Phys. Lett. 82, 364-366 (2003).

12. Garstecki, P. et al. Formation of monodisperse bubbles in a microfluidic flow-focusing device. Appl. Phys. Lett. 85, 2649-2651 (2004).

13. Garstecki, P., Stone, H. A. \& Whitesides, G. M. Mechanism for flow-rate controlled breakup in confined geometries: A route to monodisperse emulsions. Phys. Rev. Lett. 94, 164501 (2005).

14. Takeuchi, S., Garstecki, P., Weibel, D. B. \& Whitesides, G. M. An axisymmetric flow-focusing microfluidic device. Adv. Mater. 17, 1067-1072 (2005).

15. Yobas, L., Martens, S., Ong, W. L. \& Ranganathan, N. High-performance flow-focusing geometry for spontaneous generation of monodispersed droplets. Lab Chip. 6, 1073-1079 (2006).

16. Martín-Banderas, L. et al. Flow focusing: A versatile technology to produce size-controlled and specific-morphology microparticles. Small 1, 688-692 (2005).

17. Martín-Banderas, L. et al. Towards a high throughput production of uniform encoded microparticles. Adv. Mater. 18, 559-564 (2006).

18. Walzel, P. \& Schaldach, G. Herstellen feinteiliger emulsionen in viskosen flüssigkeiten. Chem. Ing. Technol. 78, 759-764 (2006).

19. Gañán-Calvo, A. M. \& Riesco-Chueca, P. Jetting-dripping transition of a liquid jet in a lower viscosity co-flowing immiscible liquid: The minimum flow rate in flow focusing. J. Fluid Mech. $\mathbf{5 5 3}$ 75-84 (2006).

20. Rosi, N. L. \& Mirkin, C. A. Nanostructures in biodiagnostics. Chem. Rev. 105, 1547-1562 (2005).

21. Sherwood, J. D. Tip streaming from slender drops in a nonlinear extensional flow. J. Fluid Mech. 144, 281-293 (1984).

22. Eggleton, C. D., Tsai, T.-M. \& Stebe, K. J. Tip streaming from a drop in the presence of surfactants. Phys. Rev. Lett. 87, 048302 (2001).
23. Berkland, C., Pollauf, E., Packa, D. W. \& Kim, K. Uniform double-walled polymer microspheres of controllable shell thickness. J. Control. Release 96, 101-111 (2004)

24. Bocanegra, R., Sampedro, J. L., Gañán-Calvo, A. M. \& Marquez, M. Monodisperse structured multi-vesicle microencapsulation using flow-focusing and controlled disturbance. J. Microencapsul. 22, 745-759 (2005).

25. Utada, A. S. et al. Monodisperse double emulsions generated from a microcapillary device. Science 308, 537-541 (2005)

26. Lin, S. P. \& Lian, Z. W. Absolute and convective instability of a viscous liquid jet surrounded by a viscous gas in a vertical pipe. Phys. Fluids A 5, 771-773 (1993).

27. Gordillo, J. M., Pérez-Saborid, M. \& Gañán-Calvo, A. M. Linear stability of co-flowing liquid-gas jets. J. Fluid Mech. 448, 23-51 (2001).

28. Lin, S. P. Breakup of Liquid Sheets and Jets (Cambridge Univ. Press, Cambridge, 2003).

29. Funada, T., Joseph, D. D. \& Yamashita, S. Stability of a liquid jet into incompressible gases and liquids Int. J. Multiphase Flow 30, 1279-1310 (2004).

30. Sevilla, A., Gordillo, J. M. \& Martinez-Bazan, C. Transition from bubbling to jetting in a coaxial air-water jet. Phys. Fluids 17, 018105 (2005).

31. Marín, A. G., Loscertales, I. G., Marquez, M. \& Barrero, A. Simple and double emulsions via coaxial jet electrosprays. Phys. Rev. Lett. 98, 014502 (2007).

32. Gañán-Calvo, A. M. Electro flow focusing: The high conductivity, low viscosity limit. Phys. Rev. Lett. 98, $134503(2007)$

33. Ambravaneswaran, B., Subramani, H. J., Phillips, S. D. \& Basaran, O. A. Dripping-jetting transitions in a dripping faucet. Phys. Rev. Lett. 93, 034501 (2004).

34. O'Donnell, B., Chen, J. N. \& Lin, S. P. Transition from convective to absolute instability in a liquid jet. Phys. Fluids 13, 2732-2734 (2001).

35. Gañán-Calvo, A. M., Herrada, M. A. \& Garstecki, P. Bubbling in unbounded coflowing liquids. Phys. Rev. Lett. 96, 124504 (2006).

36. Gañán-Calvo, A. M. Absolute instability of a viscous hollow jet. Phys. Rev. E 75, 027301 (2007).

37. Leib, S. J. \& Goldstein, M. E. Convective and absolute instability of a viscous liquid jet. Phys. Fluids 29, 952-954 (1986).

\section{Acknowledgements}

This work is supported by the Ministry of Education and Science, Project no. DPI2004-07197, and by the Junta de Andalucía, Excellence Project no. TEP 1190.

Correspondence and requests for materials should be addressed to A.M.G.C.

\section{Author contributions}

A.M.G.C.: project planning, experimental work, data analysis, theoretical work, article writing R.G.P.: experimental work, data analysis; P.R.C.: theoretical work, article writing; M.A.H.: numerical work; M.F.M.: project planning.

Competing financial interests

The authors declare no competing financial interests.

Reprints and permission information is available online at http://npg.nature.com/reprintsandpermissions/ 